\title{
A STUDY ON MEDICINE UTILIZATION PATTERN IN OUTPATIENT DEPARTMENTS OF TERTIARY GARE GENTRE IN KATHMANDU
}

\author{
Thapa $R^{1}$, Singh $\mathcal{S}^{2}$
}

${ }^{1}$ Department of Pharmacology, ${ }^{2}$ Department of Physiology, Nepal Medical College Teaching Hospital, Attarkhel, Gokarneshwor-8, Kathmandu, Nepal

\section{ABSTRACT}

The main objective of this study is to analyze the prescribing pattern of medicine in outpatient departments of tertiary care centre in Kathmandu using World Health Organization (WHO) drug use prescribing indicators. As per WHO consideration, 100 prescriptions were taken from each outpatient departments (OPD) of Nepal medical college including Orthopedics, Obstetrics and Gynecology, Surgery, Medicine, Ophthalmology, Otorhinolaryngology, Pediatrics, Dermatology and Psychiatry. Analysis of variance (ANOVA) was used to assess the statistical significance between means between all departments. Among a total of $900,47.7 \%$ were male and $52.3 \%$ were female. Average medicine per prescription was $2.43 \pm 0.039$. Number of Medicines by generic name 76 (3.4\%), antibiotics 416 (19.0\%), Injection 34 (1.5\%), from Essential Medicine List (EML) 1,312 (60.1\%), Fixed Dose Combination (FDC) $468(21.4 \%)$ and the polypharmacy ( $\geq 4)$ was $129(14.3 \%)$. The average cost was NPR 404.72 \pm 19.3 (3.69\$; $1 \$=109.41 \mathrm{NPR})$ and duration of treatment was $16.43 \pm 0.73$ days. Patient's age had positive correlation with number of medicines $(\mathrm{p}=0.002)$ and negative correlation with antibiotics $(\mathrm{p}=0.988)$. Cost of treatment had positive correlation with number of medicines $(p=0.00)$, EML $(p=0.00)$, duration of treatment $(\mathrm{p}=0.00)$ and antibiotics $(\mathrm{p}=0.33)$. Average medicines, from EML, and antibiotic use were high in Otorhinolaryngology with statistical significance of difference between mean. Prescription with FDC and intravenous were significantly high in Obstetrics and Gynecology. Cost and treatment duration were significantly high in Psychiatry. Tertiary healthcares need to develop and implement specific guidelines for prescriptions writing and also should develop a system to record them.

\section{KEYWORDS}

Essential Medicine List, Medicine utilization, Polypharmacy, WHO Drug Use prescribing Indicator

\section{CORRESPONDING AUTHOR}

Mr. Rudip Thapa

Department of Pharmacology,

Nepal Medical College Teaching Hospital,

Gokarneshwor-8, Kathmandu, Nepal

Email: thaparudip88@gmail.com

ORCID ID: 0000-0002-4846-896X

DOI: https://doi.org10.3126/nmcj.v21i4.27630 


\section{INTRODUCTION}

The prescribing pattern determines the patients exposure to medicines and has a essential role in the treatment of disease. ${ }^{1}$ The World Health Organization (WHO) in 1997 has defined medicine utilization study as "the marketing, distribution, prescription and use of drugs in a society with special emphasis on the resulting medical, social and economic consequences". ${ }^{2}$ Medicine prescribing pattern study being a part of pharmacoepidemiology describes the amount, types and determinants of medicine use. ${ }^{3}$ It explains the extent and profile of medicine use, trends, quality of medicine, and compliance with national guidelines, usage of medicine from essential medicine list and use of generic medicines. Medicine prescribing pattern varies among different geographical areas and is influenced by patient characteristics, type of disease prevalence, socioeconomic condition, accessibility of newer medicines and prescribing habit of physicians. ${ }^{4}$ These types of studies helps to monitor, evaluate and suggest modifications needed in prescribing patterns to make medicine use more rational and economical. ${ }^{5}$ The prescribing pattern monitoring essential especially in developing countries because of a increasing production and marketing of new medicines, variations in prescribing practice among physicians, concern about bizarre effects of medicines and treatment expenditure. ${ }^{6}$ Irrational prescription of medicine is a common occurrence in clinical practice. ${ }^{7}$

The main objective of this study is to analyze the prescribing pattern of medicine in outpatient departments, to compare the rational use of medicines between all departments, to find the frequency of medicines and average cost per prescription in each department and to measure the degree of polypharmacy. Monitoring of prescriptions using WHO prescribing indicators will spot the problems and provide feedback so as to create awareness about rational use of medicine. ${ }^{8}$

\section{MATERIALS AND METHODS}

This is a cross sectional study which was conducted at outpatient departments at Nepal Medical College Teaching Hospital over 6 months period from September 2018 to February 2019. Ethical approval was taken from Institutional Review and Research Committee of Nepal Medical College (Ref. No. 019-07/076). Prescriptions issued to the all out patients for the first visit was included. Incomplete prescription i.e. not having dosage form, routes of administration, duration of therapy and prescriptions on follow up was excluded. Patients were invited to participate in the study after taking informed consent. A specific questionnaire form was filled using WHO drug use prescribing indicators (WHO, 1993). ${ }^{9}$ As per WHO consideration, 100 prescriptions were taken from each outpatient departments (OPD) including Orthopedics, Obstetrics and Gynecology, Surgery, Medicine, Ophthalmology, Otorhinolaryngology (ENT), Pediatrics, Dermatology and Psychiatry i.e. in total 900 prescriptions were assessed.

Data was analyzed using Statistical Package for the Social Sciences (SPSS) version 16. Data was expressed as frequency, percentage, mean and standard error (SE). Associations between agegroup and number of medicines prescribed or number of antibiotics prescribed per encounter was analyzed using the Pearson's correlation with adjusted standardized residuals. Analysis of variance (ANOVA) was used to assess the statistical significance between means between all departments. A p-value $<0.05$ was considered to be statistically significant.

\section{RESULTS}

A total of 900 prescriptions were assessed, that included nine outpatient departments. All of the prescriptions were handwritten. In that $47.7 \%$ were of male and $52.3 \%$ were of female. Total number of medicine prescribed was 2,183 . Average medicine per prescription was $2.43 \pm 0.039$. Number of prescriptions with single medicines was 188 (20.9\%) and the polypharmacy ( $\geq 4)$ was 129 (14.3\%). Number of medicines prescribed by generic name $76(3.4 \%)$, antibiotics 416 (19\%), injection (IV) 34 (1.5\%), from Essential Medicine List (EML) 1,312 (60.1\%) and Fixed Dose Combination (FDC) was 468 (21.4\%). The average cost of medicine per prescription was Nepalese Rupees (NPR) 404.7 \pm 19.3 (3.69\$; $1 \$=109.41 \mathrm{NPR}$ ) and duration of treatment was $16.4 \pm 0.73$ days. The prescribing drugs as tablets were 1,191 (54.55\%) and capsules were $184(8.4 \%)$, while liquid suspension were 365 (16.7\%), IV were 34 (1.5\%), and topical medicines were 409 (18.7\%).

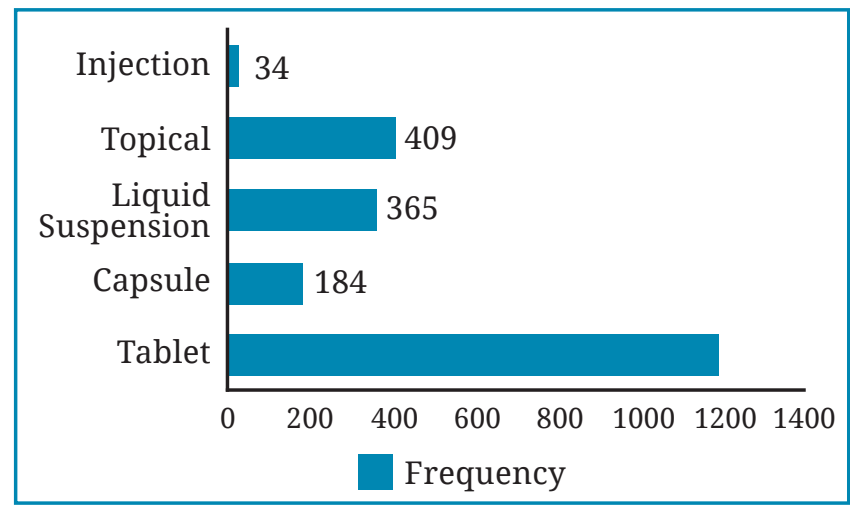

Fig 1: Frequency distribution of Dosage form 
Patient's age had positive correlation with number of medicines i.e. $r(198)=0.002, p=0.964$ and negative correlation with antibiotics i.e. $r(198)=-0.101, p=0.00$. Cost of treatment has positive correlation with number of medicines prescribed i.e. $\mathrm{r}(198)=0.408, \mathrm{p}=0.00$, prescribed from EML i.e. $r(198)=0.155, p=0.00$ and duration of treatment i.e. $\mathrm{r}(198)=0.398, \mathrm{p}=0.00$. A positive correlation was found between cost and antibiotics i.e. $r(198)=0.032, p=0.336$ with no statistical significance difference as shown in Table 1.

\section{Table 1: Pearson's correlation table among variables}

\begin{tabular}{|c|c|c|c|c|c|c|c|c|c|c|}
\hline $\mathrm{SN}$ & Variables & 1 & 2 & 3 & 4 & 5 & 6 & 7 & 8 & 9 \\
\hline 1 & Age & & & & & & & & & \\
\hline 2 & $\begin{array}{l}\text { Number of Medicine } \\
\text { per Prescription }\end{array}$ & .002 & & & & & & & & \\
\hline 3 & $\begin{array}{l}\text { Prescribed by Generic } \\
\text { Name }\end{array}$ & -.001 & $.198^{* *}$ & & & & & & & \\
\hline 4 & Antibiotic Prescribed & $-.101^{* *}$ & $.391^{* *}$ & .052 & & & & & & \\
\hline 5 & Injection Prescribed & .006 & .053 & .035 & $-.074^{*}$ & & & & & \\
\hline 6 & Prescribed from EML & $-.155^{* *}$ & $.604^{* *}$ & $.140^{* *}$ & $.394^{* *}$ & $.067^{*}$ & & & & \\
\hline 7 & FDC & $-.103^{* *}$ & $.361^{* *}$ & .007 & $.125^{* *}$ & $.092^{* *}$ & $.507^{* *}$ & & & \\
\hline 8 & Cost of Treatment & $.168^{* *}$ & $.408^{* *}$ & $.113^{* *}$ & .032 & $.164^{* *}$ & $.155^{* *}$ & $.112^{* *}$ & & \\
\hline 9 & $\begin{array}{l}\text { Duration of } \\
\text { Treatment }\end{array}$ & $.205^{* *}$ & -.021 & -.006 & $-.177^{* *}$ & .038 & -.029 & .003 & $.398^{* *}$ & \\
\hline
\end{tabular}

\begin{tabular}{|c|c|c|c|c|c|c|c|}
\hline Departments & $\begin{array}{l}\text { Sex } \\
M=\text { male } \\
F=\text { female }\end{array}$ & $\begin{array}{c}\text { Number } \\
\text { of Drug } \\
n\end{array}$ & $\begin{array}{l}\text { Generic } \\
\text { Name } \\
\text { n (\%) }\end{array}$ & $\begin{array}{c}\text { Antibiotic } \\
\text { prescribed } \\
\text { n (\%) }\end{array}$ & $\begin{array}{c}\text { Injection } \\
\text { prescribed } \\
\text { n (\%) }\end{array}$ & $\begin{array}{l}\text { Prescribed } \\
\text { from EML } \\
\text { n (\%) }\end{array}$ & $\begin{array}{c}\text { FDC } \\
\text { n (\%) }\end{array}$ \\
\hline Pediatrics & $\begin{array}{l}\mathrm{M}=61 \% \\
\mathrm{~F}=39 \%\end{array}$ & 244 & $13(5.8 \%)$ & 37 (16.5\%) & $0(0)$ & $152(67.8 \%)$ & $\begin{array}{c}54 \\
(24.1 \%)\end{array}$ \\
\hline Medicine & $\begin{array}{l}M=55 \% \\
F=45 \%\end{array}$ & 264 & $22(8.3 \%)$ & $20(7.5 \%)$ & $3(1.1 \%)$ & $163(61.7 \%)$ & $45(17 \%)$ \\
\hline Ophthalmology & $\begin{array}{l}\mathrm{M}=47 \% \\
\mathrm{~F}=53 \%\end{array}$ & 170 & $3(1.7 \%)$ & $71(41.7 \%)$ & $1(0.5 \%)$ & 77 (45.2\%) & $29(17 \%)$ \\
\hline Gynecology & $\begin{array}{l}M=0 \% \\
F=100 \%\end{array}$ & 251 & $16(6.3 \%)$ & $36(14.3 \%)$ & $16(6.3 \%)$ & $226(90 \%)$ & $\begin{array}{c}102 \\
(40.6)\end{array}$ \\
\hline Surgery & $\begin{array}{l}M=59 \% \\
F=41 \%\end{array}$ & 242 & $9(3.7 \%)$ & $63(26 \%)$ & $4(1.6 \%)$ & 137 (56.6\%) & $\begin{array}{c}53 \\
(21.9 \%)\end{array}$ \\
\hline Orthopedic & $\begin{array}{l}M=51 \% \\
F=49 \%\end{array}$ & 231 & $9(3.8 \%)$ & $3(1.3 \%)$ & $1(0.4 \%)$ & $101(43.7 \%)$ & $\begin{array}{c}50 \\
(21.6 \%)\end{array}$ \\
\hline ENT & $\begin{array}{l}\mathrm{M}=54 \% \\
\mathrm{~F}=46 \%\end{array}$ & 307 & $0(0)$ & $96(31.2 \%)$ & $0(0)$ & $254(82.7 \%)$ & $\begin{array}{c}96 \\
(31.2 \%)\end{array}$ \\
\hline Psychiatry & $\begin{array}{l}\mathrm{M}=62 \% \\
\mathrm{~F}=38 \%\end{array}$ & 229 & $3(1.3 \%)$ & $1(0.43 \%)$ & $4(1.7 \%)$ & $84(26.7 \%)$ & $21(9.2 \%)$ \\
\hline Dermatology & $\begin{array}{l}\mathrm{M}=40 \% \\
\mathrm{~F}=60 \%\end{array}$ & 245 & $1(0.4 \%)$ & 89 (36.3\%) & $5(2 \%)$ & $118(48.1 \%)$ & $18(7.3 \%)$ \\
\hline Total & $\begin{array}{l}M=47.7 \% \\
F=52.3 \%\end{array}$ & 2183 & $76(3.4 \%)$ & 416 (19\%) & $34(1.5 \%)$ & $\begin{array}{c}1312 \\
(60.1 \%)\end{array}$ & $\begin{array}{c}468 \\
(21.4 \%)\end{array}$ \\
\hline
\end{tabular}




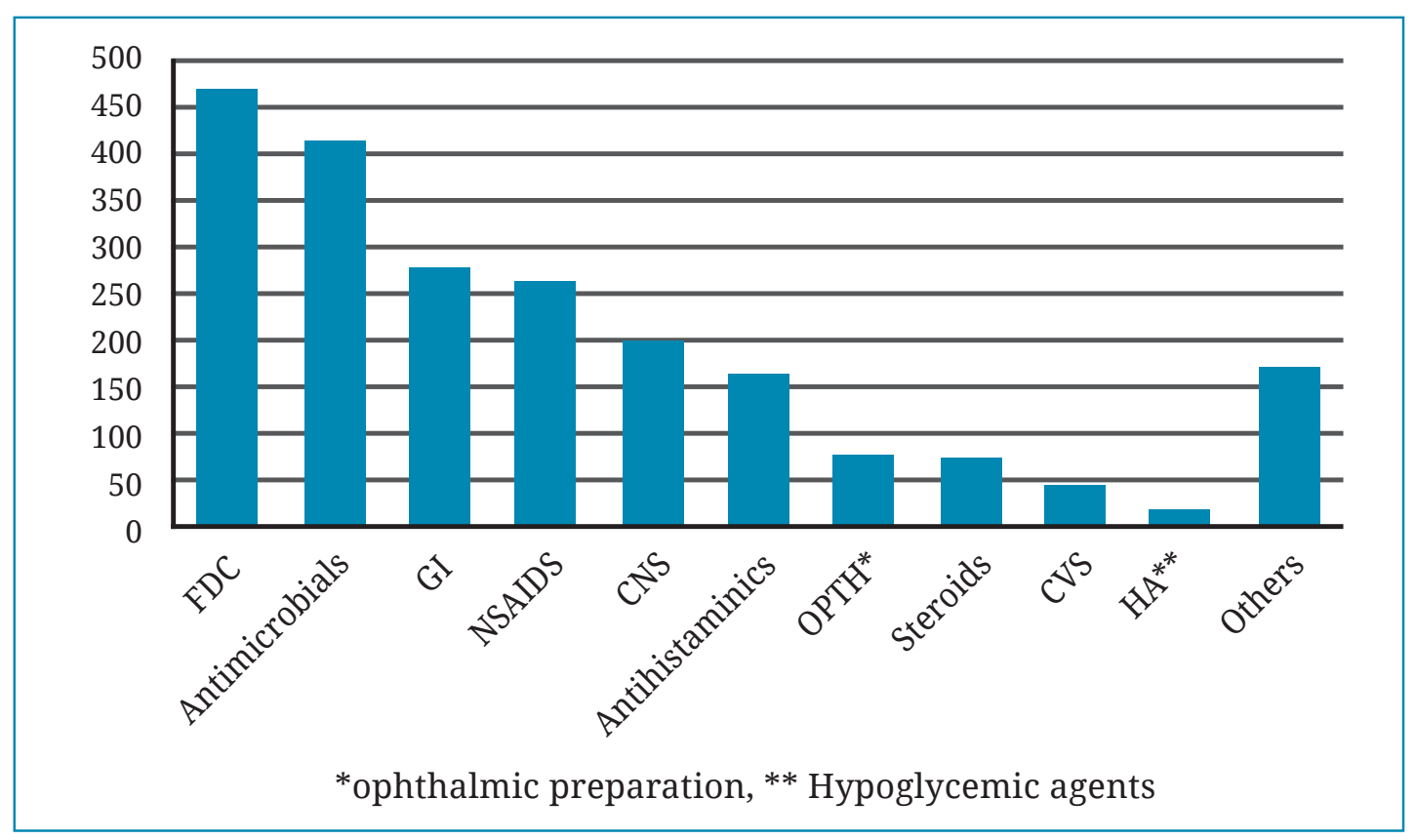

Fig 2: Frequency of different class of medicines

Table 3: Comparison of mean of the variables between outpatient departments using ANOVA (One-way).

\begin{tabular}{|c|c|c|c|c|c|c|c|c|}
\hline Department & $\begin{array}{c}\text { Average } \\
\text { no of } \\
\text { drug } \\
(\mathrm{n} \pm \mathrm{SE})\end{array}$ & $\begin{array}{c}\text { Generic } \\
\text { names } \\
(n \pm S E)\end{array}$ & $\begin{array}{c}\text { Antibiotic } \\
(\mathrm{n} \pm \mathrm{SE})\end{array}$ & $\begin{array}{c}\text { Injection } \\
(\mathrm{n} \pm \mathrm{SE})\end{array}$ & $\begin{array}{c}\text { EML } \\
(n \pm S E)\end{array}$ & $\begin{array}{c}\text { FDC } \\
(n \pm S E)\end{array}$ & $\begin{array}{c}\text { Cost } \\
(\mathrm{n} \pm \text { SE) }\end{array}$ & $\begin{array}{l}\text { Duration } \\
(n \pm S E)\end{array}$ \\
\hline Pediatrics & $2.44 \pm 0.11$ & $0.13 \pm 0.03$ & $0.37 \pm 0.03$ & $0.00 \pm 0.0$ & $1.52 \pm 0.11$ & $0.54 \pm 0.07$ & $172.1 \pm 11.9$ & $5.82 \pm 0.43$ \\
\hline Medicine & $2.64 \pm 0.16$ & $0.22 \pm 0.04$ & $0.22 \pm 0.04$ & $0.03 \pm 0.22$ & $1.63 \pm 0.13$ & $0.45 \pm 0.06$ & $643 \pm 91.5$ & $18.54 \pm 1.85$ \\
\hline Ophthalmology & $1.7 \pm 0.08$ & $0.03 \pm 0.02$ & $0.71 \pm 0.08$ & $0.1 \pm 0.01$ & $0.77 \pm 0.09$ & $0.29 \pm 0.04$ & $164.98 \pm 11.8$ & $14.96 \pm 1.02$ \\
\hline Gynecology & $2.51 \pm 0.1$ & $0.16 \pm 0.04$ & $0.36 \pm 0.06$ & $0.36 \pm 0.04$ & $2.26 \pm 0.12$ & $1.02 \pm 0.09$ & $544.57 \pm 53.4$ & $25.99 \pm 2.55$ \\
\hline Surgery & $2.43 \pm 0.11$ & $0.09 \pm 0.03$ & $0.63 \pm 0.06$ & $0.04 \pm 0.24$ & $1.37 \pm 0.12$ & $0.53 \pm 0.07$ & $492.02 \pm 57.4$ & $13.34 \pm 2.08$ \\
\hline Orthopedic & $2.31 \pm 0.09$ & $0.09 \pm 0.03$ & $0.03 \pm 0.01$ & $0.01 \pm 0.1$ & $1.01 \pm 0.12$ & $0.5 \pm 0.06$ & $229 \pm 37.814$ & $7 \pm 0.54$ \\
\hline ENT & $3.07 \pm 0.12$ & $0.00 \pm 0.00$ & $0.96 \pm 0.07$ & $0.0 \pm 0.0$ & $2.54 \pm 0.14$ & $0.96 \pm 0.02$ & $308.88 \pm 22.7$ & $7 \pm 0.22$ \\
\hline Psychiatry & $2.29 \pm 0.07$ & $0.03 \pm 0.02$ & $0.01 \pm 0.01$ & $0.04 \pm 0.24$ & $0.84 \pm 0.01$ & $0.21 \pm 0.04$ & $697.54 \pm 87.4$ & $43 \pm 3.99$ \\
\hline Dermatology & $2.45 \pm 0.1$ & $0.01 \pm 0.01$ & $0.89 \pm 0.08$ & $0.05 \pm 0.22$ & $1.18 \pm 0.11$ & $0.18 \pm 0.04$ & $390.39 \pm 44.2$ & $12.13 \pm 0.75$ \\
\hline Total & $2.43 \pm 0.039$ & $0.8 \pm 0.11$ & $0.46 \pm 0.024$ & $0.04 \pm 0.007$ & $1.46 \pm 0.04$ & $0.52 \pm 0.04$ & $404.72 \pm 19.3$ & $16.43 \pm 0.73$ \\
\hline $\begin{array}{l}\text { ANOVA } \\
\text { (one-way) } \\
\text { P-value }\end{array}$ & $\begin{array}{l}F=10.27 \\
p=0.000\end{array}$ & $\begin{array}{c}F=5.4 \\
p=0.000\end{array}$ & $\begin{array}{l}F=31.82 \\
p=0.000\end{array}$ & $\begin{array}{c}F=5.92 \\
p=0.000\end{array}$ & $\begin{array}{l}F=26.23 \\
p=0.000\end{array}$ & $\begin{array}{l}F=20.43 \\
p=0.000\end{array}$ & $\begin{array}{l}F=13.71 \\
p=0.000\end{array}$ & $\begin{array}{l}F=39.08 \\
p=0.000\end{array}$ \\
\hline
\end{tabular}

The difference in average number of medicine, prescribed by generic name, antibiotic, injection, EML prescribed, FDC prescribed, cost and duration of treatment between all the outpatient departments were statistically significant with p-value less than 0.01 as shown in Table 3 . The percentage of drugs prescribed as generic name ranged from ENT $(0.0 \%)$ to Medicine (8.3\%). The percentages in other departments are Pediatric (5.8\%), Ophthalmology (1.7\%), Gynecology (6.3\%), Surgery (3.7\%), Orthopedic (3.8\%), Psychiatry (1.3\%) and Dermatology
$(0.4 \%)$ as shown in Table 2. Interdepartmental differences were statistically significant $(F=5.4$, $\mathrm{p}=0.000$ ). The percentage of drugs prescribed as antibiotic ranged from Psychiatry $(0.43 \%)$ to ENT (31.2\%). Interdepartmental differences were statistically significant $(F=31.82, p=0.000)$. The percentage of drugs prescribed from the EML ranged from Ophthalmology (45.2\%) to ENT (82.7\%). Interdepartmental differences were also statistically significant $(\mathrm{F}=26.23, \mathrm{p}=0.000)$. The differences in average cost of medicine ranged from NPR 164.8 in Ophthalmology to 
NPR 697.5 in Psychiatry which also varied between all departments as shown in Table 3. Interdepartmental differences were also statistically significant $(\mathrm{F}=13.71, \mathrm{p}=0.000)$. The duration of treatment ranged from 5.82 days in Pediatric to 43 days in Psychiatry. Interdepartmental differences were also statistically significant $(F=39.08, p=0.000)$. The difference in average number of medicine, prescribed by generic name, antibiotic, injection, EML prescribed, FDC prescribed, cost and duration of treatment between all the outpatient departments were statistically significant with p-value less than 0.01 as shown in Table 3 .

Total prescriptions containing antibiotics were 416 (19\%), FDC 468 (21.4\%), Non Steroidal Anti Inflammatory Drugs (NSAIDS) 262 (12.0\%), Central Nervous System (CNS) 202 (9.2\%), antihistaminic 166 (7.6\%), ophthalmic preparations 80 (3.6\%), steroids 75 (3.4\%), hypoglycemic agents $20(0.9 \%)$ and others 173 (7.9\%) (Fig.2). The most groups of antibiotics prescribed included Penicillin 41 (4.6\%), Cephalosporin 57 (6.3\%), Fluroquinolones 46 (5.1\%), Macrolides 43 (4.8\%), Tetracyclines 10 (1.1\%), antifungal 67 (7.4\%), antiviral 24 (2.7\%), antiamoebic 19 (2.1\%), anthelminthic 15 (1.7\%), Amynoglycosides 6 (0.7\%), Mupirocins 32 (3.6\%) and antiseptics 18 (2\%). Among gastrointestinal (GI) medicines, Pantoprazole 128 (14.2\%) was the most often prescribed drug along with Esmoprazole 36 (4\%), Rabeprazole 43 (4.8\%), Omeprazole 26 (2.9\%), Ranitidine 10 (1.1\%), Ondansetron 11 (1.2\%) and Hyoscine 22 (2.4\%). Other classes of medicines prescribed includes FDC 468 (21.4\%), NSAIDs 262 (12\%), CNS 202 (9.2\%), antihistaminic 166 (7.6\%), ophthalmic preparations 80 (3.6\%), steroids 75 (3.4\%), hypoglycemic agents $20(0.9 \%)$ and others 173 (7.9\%).

The most commonly prescribed NSAIDS were Acetaminophen 72 (8\%), Aceclofenac 28 (3.1\%), Diclofenac 21 (2.3\%), Paracetamol 12 (1.3\%) and Flurbuprofen $6(0.7 \%)$. The most commonly prescribed CVS medicines were Losartan 12 (1.3\%), Amlodopine 12 (1.3\%), Atenelol 2 (0.2\%), Atrovastatin $7(0.8)$ and Furosemide 6 (0.7\%). The most commonly prescribed steroids were Beclomethosone 21 (2.3\%), Hydrocortisone 17 (1.9\%), Flurmetholone $15 \quad(1.7 \%)$ and Methylprednisolone14(1.6\%).The most commonly prescribed CNS medicines were Lorazepam 41 (4.6\%), Esitalopram 32 (3.6), Clonazepam 39 (4.3\%), Diazepam 20 (2.2\%), Olanzepine 23 (2.6\%), Mitrazepam 8 (0.9\%), Alprazolam 14 (1.6\%), Domeperidone 7 (0.8\%) and other antidepressants $18(2.0 \%)$. The most commonly prescribed ophthalmic preparations were Fluorometholone 14 (1.5\%) and Carboxymthylcellulose 45 (4.7\%). The most commonly prescribed
FDC were Ibuprofen+Paracetamol 149 (16.6\%), Amoxicillin+Clavulanic 39 (4.1\%), Paracetamol+Chlorzoxazone 31 (3.4\%), eye drop Polyvinyl alcohol+Povidone 21 (2.3\%), antacid 32 (3.6\%), Liquid Paraffin+Magnesium hydroxide+Sodium Picosulfate 15 (1.7\%) and multivitamins 111 (12.3\%). The most commonly prescribed other medicines were Oxymetazoline 21 (2.3\%), Dextromethorphan 31 (3.4\%), Iron 37 (4.1\%), Calcium 40 (4.4\%), Folic acid 14 (1.6\%), Lignocaine 9 (1.0\%), Tamsulosin 6 (0.8\%), Metformin 14 (1.5\%) and Glimeperide 6 (0.6\%).

\section{DISCUSSION}

The average number of medicine per prescription in this study was 2.84 which is higher than WHO reference value (1.6-1.8). ${ }^{10}$ The higher values were also found in other similar studies done in Nepal at different University teaching hospital by Thapa et al (2.7), ${ }^{11}$ Lamichhane et al (1.9), ${ }^{12}$ Pradhan et al $(2.2)^{13}$ and Sarraf et al (4.6). ${ }^{14}$

The incidence of polypharmacy was $14 \%$ which is similar with the studies done by Hussain et al (21.30\%), ${ }^{15}$ Moses et al (19\%) ${ }^{16}$ and Asiri et al (22.1\%). ${ }^{17}$ The reason behind the polypharmacy may be due to patient's demand, desire to treat several comorbid conditions at the same time and inappropriate diagnosis for definitive cause of disease. ${ }^{18}$ There is a need to educate the patients and prescribers on the hazards of polypharmacy.

The percentage of generic name prescription was $3.4 \%$ which is much lower WHO reference value (should be 100\%). ${ }^{10}$ This is lower than reported by Dahal et al (59.02\%), ${ }^{19}$ Ferreira et al $(86 \%),{ }^{20}$ Desalegn et al $(98.7 \%)^{21}$ and Momtaz et al $(45.6 \%){ }^{22}$ WHO always promotes the use of generic name of medicines as they are cheaper than branded substitutes and have equal efficacy and potency. The lower rate in Nepal may be due to the influence of local and international pharmaceutical companies on physicians' decisions. Most of the healthcare facilities do not run their own hospital pharmacy and have to depend on private retail pharmacy for dispensing the medicine which may create the trust issue between physician, patient and dispensaries when generic names are prescribed.

The use of antibiotic in this study was $19.0 \%$ and is within the WHO reference value (20-26.8\%). ${ }^{10}$ The finding is similar with the studies done by Sapkota et al (18\%), ${ }^{23}$ Ahmad et al (17.7\%), ${ }^{24}$ Mahmood et al (9.8\%), ${ }^{25}$ and Edalo et al $(11.5 \%)^{26}$ and is lower in comparison to the studies done by Okoro et al (56.2\%), ${ }^{27}$ Karimi et al (45\%), ${ }^{28}$ Mittal et al $(66.7 \%)^{29}$ and Hussain et al $(28.1 \%){ }^{30}$ This may be due to inclusion of Orthopedics and Psychiatry department which has very low percentage of 
antibiotic prescription. The finding that ENT department recorded the highest number of medicine prescribed and antibiotics used is not surprising. Since, ENT department has to deal with the problems related to three organ system (ear, nose and throat) and the infection to these organs generally requires the antimicrobials therapy which contributes to high average number of medicines and antibiotic prescriptions.

The IV prescription was only $15.0 \%$ which is less than WHO reference value $(13.4-24.0 \%) .{ }^{10}$ It may be due to factors related to patient compliance regarding IV administration. The frequency of oral form was highest in this study being cheaper alternative. Injections being associated with the risk of infections are potentially harmful to patients. ${ }^{31}$ The incidence of IV prescription was high in Gynecology (6.3\%) due to vaccination of tetanus toxoid on primigravida.

Prescription from EML was 60\% which is higher while comparing with the studies done by Basnet et al $(46.1 \%)^{32}$ and Shrestha et al $(47.5 \%)$. $^{33}$ but is much lower than WHO reference value (should be $100 \%) .{ }^{10}$ It may be due to lack of awareness to the physician about the significance of positive correlation between prescribing from EML, polypharmacy, generic name prescription, antibiotics use and cost of treatment. Also absence of a copy of EML in the respective departments contributes to the low EML prescription.

FDC prescription was $21.4 \%$ which is similar with the study done by Alam et al (21.6\%), ${ }^{34}$ Poudel et al (33.5\%), ${ }^{35}$ Potharaju et al (23\%) ${ }^{36}$ and Abidi et al (26.87\%). ${ }^{37}$ FDC prescription was highest in Gynecology is due to high number of pregnant women visiting to the department and are essentially prescribed with FDC of iron, calcium and other multivitamins. Similar findings were seen in Rohra et al $(79.4 \%)^{38}$ and Nagasa et al $(34.4 \%)^{39}$ in which FDC of iron, calcium and other multivitamins were most commonly prescribed medicines during pregnancy. So, multivitamins those issued in $12.3 \%$ of cases may not be due to its deficiencies only.

The average cost of treatment was NPR $404.72 \pm 19.3$ i.e. $3.69 \$$ (Average: $1 \$=109.41 \mathrm{NPR}, 2018$ ) which only includes the medicine related expenses. The reason behind Psychiatry department having highest cost of treatment is due to high medicine per prescription, longer duration of treatment, types and severity of illness that the patient comes with. Ophthalmology and Pediatrics have least cost of treatment because of having low number of medicine per prescription and shorter duration of treatment. The medicine expenditure is a serious problem in developing countries such as Nepal. A recent study of developing countries found that the cost of the treatments were related with high frequency of antibiotics used, pharmaceutical incentives on prescribers and weak mechanisms for quality assurance. ${ }^{40}$ The low prescription of drugs with their generic names in addition to the prescription of large numbers of drugs adds to the cost of medications to patients. Efforts at reducing average cost of drugs to patients must reduce average number of drugs and more importantly increase prescription by their generic names. It is advised that such type's studies should be carried out at all levels of Nepal's healthcare system to lower government expenditure on health and improve the eminence of healthcare services.

The results are alike when comparing with national and international studies. Prescription of medicines from EML and generic names do not meet up WHO standard. The prescribing patterns of antibiotics and injectable medications were found to be satisfactory compared to the WHO standard. On the contrary, the extent of polypharmacy was low. For rational prescription writing, healthcare facilities need to develop and implement specific guidelines and also should develop a system to record them. Continuing professional development programs are essential for prescribing more rational and safer drugs, hence successful medicine therapy. Prescribing pattern can become better by emphasizing on medical curricula and should be based on the use of essential medicines. It is crucial to raise the population's awareness of generic drugs so as to strengthen the trust in the behavior of physicians and pharmacists.

\section{ACKNOWLEDGEMENT}

I would like to express my sincere gratitude to Mr. Nirab Bhattrai and Mr. Dipesh Joshi for their encouragement and guidance throughout this study. My heartfelt gratitude also goes to Mr. Prem Prasad Panta, Biostatistician, Department of Community Medicine for helping me in statistical part and analysis of data. I am in debt to the patients for their participation and staffs of outpatient department for their support and corporation.

\section{REFERENCES}

1. Summoro TS, Gidebo KD, Kanche ZZ, Woticha EW. Evaluation of trends of drug-prescribing patterns based on WHO prescribing indicators at outpatient departments of four hospitals in southern Ethiopia. Drug Des Devel Ther 2015; 9: 4551-7.

2. WHO. International Working Group for Drug Statistics Methodology, WHO Collaborating Centre for Drug Statistics Methodology \& WHO 
Collaborating Centre for Drug Utilization Research and Clinical Pharmacological Services. Introduction to drug utilization research 2003. 1-49.

3. Sjoqvist F, Birkett D. Drug Utilization. In: Bramley DW editor. Introduction to Drug Utilization Research. (WHO booklet) New York: WHO office of publications; 2003. 76-84.

4. Rode SB, Ajagallay RK, Salankar HV, Sinha U. A study on drug prescribing pattern in psychiatry outpatient department from a tertiary care teaching hospital. Int'l J Basic Clin Pharmacol 2014; 3: $517-22$.

5. Gupta N, Sharma D, Garg SK, Bhargava VK. Auditing of prescriptions to study utilization of antimicrobials in tertiary hospital. Indian J Pharmacol 1997; 29: 411-5.

6. Strom BL, Stephan EK, editors. Pharmacoepidemiology. 3rd ed.Wiley-Blackwell: John Wiley and Sons, English; 2000. 231

7. Ramsay LE. Bridging the gap between clinical pharmacology and rational drug prescribing. $\mathrm{Br} J$ Clin Pharmacol 1993; 35: 575-6.

8. Pradhan SC, Shewade DG, Shashindren $\mathrm{CH}$, Bapna JS. Drug utilization studies. Nat'l Med J India 1988; 1: $185-9$.

9. WHO. How to investigate drug use in health facilities: Selected drug use indicators 1993, Technical Report Series 7.

10. Isah AO, Ross-Degnan D, Quick J, Laing R, Mabadeje AF. The Development of Standard Values for the WHO Drug use Prescribing Indicators. ICUM/EDM/ WHO. 1997.

11. Thapa R, Rai P, Mahara L, Kulshrestha VK. A comparative study of rational use of medicines between public and private hospitals of kathmandu, nepal. Nepal Med Coll J 2018; 20: 83-7.

12. Lamichhane DC, Giri BR, Pathak OK, Panta OB, Shankar PR. Morbidity profile and prescribing patterns among outpatients in a teaching hospital in Western Nepal. Mcgill J Med 2006; 9: 126-33.

13. Pradhan M, Mathur M. Evaluation of prescribing indicators and pattern among dermatological outpatients in a teaching hospital of central Nepal. J Coll Med Sci Nepal 2016; 12: 44-9.

14. Sarraf DP, Rauniar GP, Misra A. Drug utilization pattern in four major wards of a tertiary hospital in eastern Nepal. Health Renaiss 2015; 13: 50-65.

15. Hussain S, Yadav SS, Sawlani KK, Khattri S. Assessment of drug prescribing pattern using world health organization indicators in a tertiary care teaching hospital. Indian J Public Health 2018; 62: 156-8.

16. Moses AO, Cecilia II, Thomas E. Prescribing patterns and perceptions of health care professionals about rational drug use in a specialist hospital clinic. $J$ Public Health Africa 2014; 5: 99-103.

17. Asiri YA, Al-Arifi MN. Polypharmacy and patterns in drug prescribing at a primary healthcare centre in the Riyadh region of Saudi Arabia. Int'l J Pharm Pract 2011; 19: 123-8.
18. Erah PO, Olumide GO and Okhamafe AO. Prescribing practices in two health care facilities in Warri, Southern Nigeria: a comparative study. Trop J Pharm Res 2003; 2: 175-82.

19. Dahal P, Bhattarai B, Adhikari D, Shrestha R, Baral SR, Shrestha N. Drug use pattern in primary health care facilities of kaski district, western nepal. Sunsari Tech Coll J 2012; 1: 1-8.

20. Ferreira MBC, Heineck I, Flores LM et al. Rational use of medicines: prescribing indicators at different levels of health care. Brazl J Pharm Sci 2013; 49: 3329-40.

21. Desalegn AA. Assessment of drug use pattern using WHO prescribing indicators at Hawassa University teaching and referral hospital, south Ethiopia: a cross-sectional study. BMC Health Serv Res 2013; 13: $170-6$.

22. Momtaz H, Tomalika N, Mohsena, M et al. Morbidity and drug prescribing patterns at a rural primary health care center of Bangladesh. IMC J Med Sci 2018; 12: 50-6.

23. Sapkota S, Pudasaini N, Singh C, GC S. Drug prescribing pattern and prescription error in elderly: a retrospective study of inpatient record. Asian J Pharm Clin Res 2011; 4: 129-32.

24. Ahmad AA, Sayer IA, Karem HA, Mohammad S, Majed MM. Evaluation of drug-prescribing patterns based on the WHO prescribing indicators at outpatient clinics of five hospitals in Jordan:a cross-sectional study. Int'l J Clin Pharmacol Ther 2017; 55: 1-8.

25. Mahmood A, Elnour AA, Ali AA, Hassan NA, Shehab A, Bhagavathula AS. Evaluation of rational use of medicines (RUM) in four government hospitals in UAE. Saudi Pharm J 2016; 24: 189-96.

26. Edalo AS. Drug Prescribing Pattern among Physicians in an Outpatient Department of Tertiary Hospital, KSA. Brit J Pharm Res 2015; 5: 117-23.

27. Okoro RN, Shekari BG. Physicians’ drug prescribing patterns at the national health insurance scheme unit of a teaching hospital in the North Eastern Nigeria. Arch Pharma Pract 2013; 4: 3-8.

28. Karimi A, Haerizadeh M, Soleymani F, Haerizadeh M, Taheri F. Evaluation of medicine prescription pattern using World Health Organization prescribing indicators in Iran: A cross-sectional study. J Res Pharm Pract 2014; 3: 39-45.

29. Mittal N, Mittal R, Singh I, Shafiq N, Malhotra S. Drug Utilization study in a Tertiary Care Center: Recommendations for Improving Hospital Drug Dispensing Policies. Indian J Pharm Sci 2014; 9: 30814.

30. Hussain NA, Adebayo ET. Pattern of prescription drug use in Nigerian army hospitals. Ann Afr Med 2010; 9: 152-8.

31. Rechel B, Kennedy C, McKee M, Rechel B. The Soviet legacy in diagnosis and treatment: Implications for population health. J Public Health Policy 2011; 32: 293-304.

32. Basnet S, Paudel KR, Sah AK et al. Prescribing pattern, polypharmacy and potentially inappropriate prescribing in hospitalized elderly patients: a retrospective study in a teaching hospital in Nepal. Int'l J Sci Rep 2016; 2: 7-12. 
33. Shrestha B, Dixit SM. Assessment of Drug Use Pattern Using WHO Prescribing Indicators. J Nepal Health Res Counc 2018; 16: 279-84.

34. Alam K, Mishra P, Prabhu M et al. A study on rational drug prescribing and dispensing in outpatients in a tertiary care teaching hospital of Western Nepal. Kathmandu Univ Med J 2006; 16: 436-43.

35. Poudel A, Mohamed IM, Mishra P, Palaian S. Assessment of utilization pattern of fixed dose drug combinations in primary, secondary and tertiary healthcare centers in Nepal: a cross-sectional study. BMC Pharmacol Toxicol 2017; 18: 1-10.

36. Potharaju HR, Kabra SG. Prescription audit of outpatient attendees of secondary level government hospital in Maharashtra. Indian J Pharmacol 2001; 43: 150-6.

37. Abidi A, Gupta S, Kansal S, Ramgopal. Prescription auditing and drug utilization pattern in a tertiary care teaching hospital of Western UP. Int'l J Basic Clin Pharm 2012; 1: 184-90.
38. Rohra DK, Das N, Azam SI et al. Drugprescribing patterns during pregnancy in the tertiary care hospitals of Pakistan: a cross sectional study. BMC Pregnancy Childbirth 2008; 8: 24-9.

39. Negasa M, Tigabu BM. Drug prescribing pattern among pregnant mothers attending obstetrics and gynecology department in Hiwot Fana Specialized Teaching Hospital, Ethiopia. Arch Pharma Pract 2014; 5: 78-83.

40. Alsan M, Schoemaker L, Eggleston K, Kammili N, Kolli P, Bhattacharya J. Out-of-pocket health expenditures and antimicrobial resistance in lowincome and middle-income countries: an economic analysis. Lancet Infect Dis 2015; 10: 1203-10. 